Katie A. Hunt, Vadivelam Murthy, Prashanth Bhat, Grenville F. Fox, Morag E. Campbell, Anthony D. Milner and Anne Greenough*

\title{
Tidal volume monitoring during initial resuscitation of extremely prematurely born infants
}

https://doi.org/10.1515/jpm-2018-0389

Received November 21, 2018; accepted April 14, 2019; previously published online May 20, 2019

\section{Abstract}

Background: Airway obstruction can occur during facemask (FM) resuscitation of preterm infants at birth. Intubation bypasses any upper airway obstruction. Thus, it would be expected that the occurrence of low expiratory tidal volumes (VTes) would be less in infants resuscitated via an endotracheal tube (ETT) rather than via an FM. Our aim was to test this hypothesis.

Methods: Analysis was undertaken of respiratory function monitoring traces made during initial resuscitation in the delivery suite to determine the peak inflating pressure (PIP), positive end expiratory pressure (PEEP), the VTe and maximum exhaled carbon dioxide $\left(\right.$ ETCO $\left._{2}\right)$ levels and the number of inflations with a low VTe (less than $2.2 \mathrm{~mL} / \mathrm{kg})$.

Results: Eighteen infants were resuscitated via an ETT and 11 via an FM, all born at less than 29 weeks of gestation. Similar inflation pressures were used in both groups (17.2 vs. $\left.18.8 \mathrm{cmH}_{2} \mathrm{O}, \mathrm{P}=0.67\right)$. The proportion of infants with a low median VTe $(\mathrm{P}=0.6)$ and the proportion of inflations with a low VTe were similar in the groups $(\mathrm{P}=0.10)$, as was the lung compliance $(\mathrm{P}=0.67)$. Infants with the lowest VTe had the stiffest lungs $(\mathrm{P}<0.001)$.

\footnotetext{
*Corresponding author: Prof. Anne Greenough, Department of Women and Children's Health, School of Life Course Sciences, Faculty of Life Sciences and Medicine, King's College London, London, UK; The Asthma UK Centre for Allergic Mechanisms in Asthma, King's College London, London, UK; NIHR Biomedical Centre at Guy's and St Thomas NHS Foundation Trust and King's College London, London, UK; and NICU, $4^{\text {th }}$ Floor Golden Jubilee Wing, King's College Hospital, Denmark Hill, London SE5 9RS, UK, Tel.: 0203 2993037; Fax: 0203 2998284, E-mail: anne.greenough@kcl.ac.uk Katie A. Hunt, Vadivelam Murthy and Prashanth Bhat: Department of Women and Children's Health, School of Life Course Sciences, Faculty of Life Sciences and Medicine, King's College London, London, UK Grenville F. Fox: Neonatal Unit, Evelina London Children's Hospital, Guy's and St Thomas' NHS Foundation Trust, London, UK Morag E. Campbell: Neonatal Unit, Southern General Hospital, Scotland, UK
}

Anthony D. Milner: The Asthma UK Centre for Allergic Mechanisms in Asthma, King's College London, London, UK
Conclusion: Respiratory function monitoring during initial resuscitation can objectively identify infants who may require escalation of inflation pressures.

Keywords: carbon dioxide; endotracheal tube; facemask; intubation; prematurity; respiratory function monitoring; resuscitation; tidal volume.

\section{Introduction}

Tidal volumes of very prematurely born infants may often be very low during initial resuscitation in the delivery suite, particularly before the infant makes an inspiratory effort. We demonstrated that expiratory tidal volumes (VTes) rarely exceeded $4.4 \mathrm{~mL} / \mathrm{kg}$, twice the anatomical dead space $[1,2]$, until the first inspiratory effort coincided with an inflation $[3,4]$. It has been suggested that these low tidal volumes during resuscitation via a facemask (FM) may be due to airway obstruction $[5,6]$. Obstruction due to FM hold and positioning has been reported [7], but others have suggested that airway obstruction may occur due to laryngeal closure [8]. Laryngeal closure is overcome by the presence of an endotracheal tube (ETT) and, therefore, the occurrence of low VTes would be expected to be less in intubated babies compared to those resuscitated by an FM. The first spontaneous breath coinciding with an inflation, which we have termed active inflation [3], resulted in higher VTe and end tidal carbon dioxide $\left(\mathrm{ETCO}_{2}\right)$ levels in infants resuscitated via an FM or an ETT [9]. The aim of this study, therefore, was to compare the VTe and $\mathrm{ETCO}_{2}$ levels prior to the first active inflation in infants during initial resuscitation via an FM or an ETT. We wished to determine whether there were significant differences between the two groups in the proportion of babies with low median VTes, that is, a median VTe less than $2.2 \mathrm{~mL} / \mathrm{kg}$ (the anatomical dead space $[1,2]$ ) or in the proportion of inflations with low VTes. Furthermore, we compared the VTes before and after intubation in a group of babies who had not made a spontaneous respiratory effort before intubation, as those results would further inform whether VTe levels remained low after intubation and 
hence strategies as well as reducing airway obstruction were needed to optimise tidal volume delivery during initial resuscitation.

\section{Materials and methods}

This was a retrospective analysis of respiratory function monitoring recordings at delivery of infants born at less than 29 weeks of gestational age who required resuscitation at birth either via an FM or an ETT. For the purposes of this study, recordings between March 2010 and March 2014 at two hospital sites were analysed. Certain results from some of the infants have been previously published [4]. Ethical approval was granted by the Outer North London Research Ethics Committee who required parental written consent only for analysis of the data which was obtained when the mother was on the postnatal ward.

\section{Resuscitation protocol}

Infants received resuscitation either via oral intubation using a size 2 or 2.5 ETT or via a round silicon FM (Marshall size 0, Airway Products Limited, Bath, UK). The decision to proceed to immediate intubation was made by the clinical team based on a heart rate of less than 60 beats/min and no respiratory effort as determined by clinical observation. Other infants were intubated if they had failed to adequately respond to FM resuscitation. No pre-medication was administered. The clinicians involved in the resuscitation of infants had all been trained in newborn life support (NLS) and had received Resuscitation Council, UK NLS provider certificates. They had also been trained to operate the respiratory function monitor. During resuscitation, the respiratory function monitor was set to display tidal volume, flow, positive inflation pressure, positive end expiratory pressure (PEEP) and $\mathrm{ETCO}_{2}$.

Positive pressure inflations were generated using a t-piece device (Neopuff Infant Resuscitator, Fisher \& Paykel Healthcare, Auckland, New Zealand) attached either to the FM or ETT. The Neopuff, a continuous flow, pressure-limited device, had a built-in manometer, a PEEP valve and a gas flow rate of $5 \mathrm{~L} / \mathrm{min}$. The pressure relief valve was set at $30 \mathrm{cmH}_{2} \mathrm{O}$. The clinicians were advised to follow the UK recommendations, that is, to use a peak inflating pressure (PIP) of 20-25 $\mathrm{cmH}_{2} \mathrm{O}$ with a PEEP level of $4-5 \mathrm{cmH}_{2} \mathrm{O}$ and to maintain each of the first five inflations for 2-3 s [10]. The PIP was to be increased if chest wall expansion was thought inadequate. All infants were initially resuscitated with an inspired fraction of oxygen $\left(\mathrm{FiO}_{2}\right)$ of 0.21 (as is used by more than $40 \%$ of UK neonatal intensive care units (NICUs) [11]). The $\mathrm{FiO}_{2}$ was subsequently increased if necessary to maintain the oxygen saturation levels between $85 \%$ and $92 \%$. Infants were intubated at one site with shouldered ETTs and straight tubes at the second site (Portex tubes, Smiths Medical, Kent, UK).

\section{Monitoring equipment}

The respiratory function monitor used was an NM3 respiratory profile monitor (RPM) (Philips Respironics, Wallingford, CT, USA).
The monitor was connected to a laptop (Dell Latitude, Dell, Bracknell, UK) with customised Spectra software (3.0.1.4) (Grove Medical, London, UK). The NM3 RPM had a combined pressure, flow and mainstream carbon dioxide $\left(\mathrm{CO}_{2}\right)$ sensor and this was placed in line between the t-piece and the FM or ETT. The NM3 monitor is automatically calibrated for flow, pressure and $\mathrm{CO}_{2}$ according to the factory stored calibration in the monitor. Flow was measured using a fixed orifice pneumotachograph. One of the tubes from the pneumotachograph was connected to a second pressure transducer to measure airway pressure. The accuracy of the pneumotachograph was confirmed using a calibration syringe. Oxygen saturation monitoring was also performed, the monitor recorded oxygen saturation and heart rate.

\section{Analysis}

The first spontaneous breath coinciding with an inflation was identified as previously described [3]. All inflations prior to the first spontaneous breath were analysed. The PIP, PEEP, inflation pressure (PIP-PEEP), inspiratory tidal volume (VTi) and VTe, ETCO, levels and the leak (the difference between the VTi and VTe, expressed as a percentage of the total inspiratory volume) were determined. A quasi static compliance was calculated by dividing VTe by PIP-PEEP. In addition, the number of infants in each group with a low median VTe, that is, less than $2.2 \mathrm{~mL} / \mathrm{kg}$ and the proportion of inflations with a low VTe (less than $2.2 \mathrm{~mL} / \mathrm{kg}$ ) prior to the first active inflation were compared between the two groups. Successful intubation was determined from the monitoring by the presence of $\mathrm{ETCO}_{2}$ and expiratory flow. In addition, the same monitoring results were assessed for five inflations at $60 \mathrm{~s}$ into resuscitation.

A further group of infants were identified who received FM ventilation, were then intubated and in whom no spontaneous breaths had been identified before intubation occurred. The VTes before and after intubation were compared in this group. We aimed to analyse the 10 inflations prior to intubation and the 10 inflations immediately after intubation, but in some cases, there were fewer than 10 inflations available for analysis.

\section{Statistical analysis}

Data were assessed for normality using the Shapiro-Wilk test and found not to be normally distributed; hence, the Mann-Whitney $U$ test, Wilcoxon signed-rank test, chi-squared $\left(\chi^{2}\right)$ test and Spearman correlation were used as appropriate to assess whether differences between groups were statistically significant. Analysis was undertaken using IBM SPSS Statistics for Windows, version 22 (IBM Corp., IBM SPSS, Armonk, NY, USA).

\section{Results}

Sixty-three traces were reviewed. Analysis was not undertaken of traces where the infant had breathed before the 
onset of positive pressure ventilation via an FM or an ETT, the infants had received continuous positive airway pressure rather than positive pressure ventilation or the recording commenced after the onset of positive pressure ventilation. In the intubated group, only infants who were successfully intubated were included.

Traces from 29 babies who had undergone initial resuscitation with an ETT or an FM were analysed. The demographics between those who were resuscitated via an ETT or via an FM were comparable (Table 1). Only one infant died in the delivery room, this was an infant intubated at birth. There were no significant differences in the number of inflations examined in the two groups (Table 2). The median time to the first active inflation was $13.5 \mathrm{~s}$ (range 2-76 s) in the ETT group and $24 \mathrm{~s}$ (range $2-82 \mathrm{~s})$ in the FM group $(\mathrm{P}=0.53)$. There were no significant differences in the PIP, PEEP, inflation pressures, $\mathrm{ETCO}_{2}$ or VTe levels between those resuscitated via an

Table 1: Demographics by resuscitation mode.

\begin{tabular}{lrrr}
\hline & FM $(\mathbf{n}=11)$ & ETT $(\mathbf{n}=18)$ & P-value \\
\hline Male & $5(45)$ & $10(56)$ & 0.6 \\
Gestational age, weeks & $27(24-29)$ & $26(23-28)$ & 0.15 \\
Birth weight, g & $860(600-1346)$ & $778(484-1070)$ & 0.28 \\
Antenatal steroids & $10(90)$ & $16(89)$ & 0.95 \\
Vaginal delivery & $6(60)$ & $15(83)$ & 0.33 \\
Apgar at 1 min & $6(0-9)$ & $5(2-8)$ & 0.47 \\
Apgar at 5 min & $8(4-10)$ & $8(5-10)$ & 0.90 \\
\hline
\end{tabular}

Data are presented as $\mathrm{n}(\%)$ or median (range).
ETT or via an FM, but the magnitude of leak was greater in the FM group ( $\mathrm{P}=0.007)$ (Table 2). In the FM group, there was a significant negative correlation between the magnitude of leak and VTe $(r=-0.627, P=0.039)$. The proportion of infants with a median VTe $<2.2 \mathrm{~mL} / \mathrm{kg}$ and the proportion of inflations with a VTe $<2.2 \mathrm{~mL} / \mathrm{kg}$ were similar in the two groups (Table 2). Comparison of infants with a low VTe and those with a VTe greater than $2.2 \mathrm{~mL} / \mathrm{kg}$ demonstrated that the only significant difference was that the former group had a lower compliance (Table 3).

After $60 \mathrm{~s}$ of monitoring, all but two infants in each of the FM and ETT groups had made a spontaneous respiratory effort. The only significant difference in the results of the two groups was the magnitude of leak, being greater in the FM group $(\mathrm{P}=0.028)$ (Table 4).

Traces from seven infants were analysed before and after intubation. These seven infants were significantly more immature than those in the FM group (median gestational age 24 compared to 27 weeks, $\mathrm{P}=0.015$ ), but otherwise there were no significant demographic differences between these infants and those in the ETT and FM groups (data not shown). In the seven infants, there was no significant difference in the median VTe achieved during FM and ETT resuscitation $(3 \mathrm{~mL} / \mathrm{kg}$ vs. $2.6 \mathrm{~mL} / \mathrm{kg}, \mathrm{P}=0.401)$. In addition, the mean VTe during FM ventilation in those infants was not significantly different to that in the FM group overall $(\mathrm{P}=0.085)$ and the mean VTe following intubation was not significantly different to the VTe of the infants in the ETT group overall $(\mathrm{P}=0.883)$.

Table 2: Outcomes by resuscitation mode.

\begin{tabular}{|c|c|c|c|}
\hline & $F M(n=11)$ & ETT $(n=18)$ & P-value \\
\hline Total number of inflations & 115 & 293 & \\
\hline Number of inflations per infant & $10(1-47)$ & $16(1-71)$ & 0.28 \\
\hline Peak inspiratory pressure (PIP), $\mathrm{cmH}_{2} \mathrm{O}$ & $22.0(13.8-31.5)$ & $22.6(20.2-34.8)$ & 0.34 \\
\hline Positive end expiratory pressure (PEEP), $\mathrm{cmH}_{2} \mathrm{O}$ & $5.0(1.0-5.9)$ & $5.1(2.0-8.4)$ & 0.44 \\
\hline Inflation pressure, $\mathrm{cmH}_{2} \mathrm{O}$ & $17.2(12.8-25.6)$ & $18.8(12.6-29.7)$ & 0.55 \\
\hline $\mathrm{VTi}, \mathrm{mL} / \mathrm{kg}$ & $8.3\left(1.8-176^{\mathrm{a}}\right)$ & $5.5(0.90-18.8)$ & 0.04 \\
\hline VTe, $\mathrm{mL} / \mathrm{kg}$ & $1.7(0.59-9)$ & $2.8(0.35-10.3)$ & 0.30 \\
\hline Compliance, $\mathrm{mL} / \mathrm{cmH}_{2} \mathrm{O}$ & $0.13(0.03-0.3)$ & $0.10(0.01-0.3)$ & 0.67 \\
\hline Compliance, $\mathrm{mL} / \mathrm{cmH}_{2} \mathrm{O} / \mathrm{kg}$ & $0.16(0.05-0.27)$ & $0.13(0.01-0.39)$ & 0.842 \\
\hline Maximum $\mathrm{ETCO}_{2}$ level, $\mathrm{kPa}$ & $0.27(0.07-4.0)$ & $0.16(0.09-6.4)$ & 0.61 \\
\hline Leak, \% & $79(15-97)$ & $37(1-95)$ & 0.007 \\
\hline Infants with a median VTe $<2.2 \mathrm{~mL} / \mathrm{kg}$ & $6(54)$ & $8(44)$ & 0.6 \\
\hline Inflations with a VTe $<2.2 \mathrm{~mL} / \mathrm{kg}$ & $180(61)$ & $94(69)$ & 0.10 \\
\hline
\end{tabular}

Data are presented as median (range) or $\mathrm{n}(\%)$. an one infant there was a very large leak. 
Table 3: Comparison of infants with a median VTe $<2.2 \mathrm{~mL} / \mathrm{kg}$ and those with a median $\mathrm{VTe}>2.2 \mathrm{~mL} / \mathrm{kg}$.

\begin{tabular}{|c|c|c|c|}
\hline & $\begin{array}{r}\text { VTe }<2.2 \mathrm{~mL} / \mathrm{kg} \\
(\mathrm{n}=14)\end{array}$ & $\begin{array}{r}\text { VTe }>2.2 \mathrm{~mL} / \mathrm{kg} \\
(\mathrm{n}=15)\end{array}$ & P-value \\
\hline Male & 7 & 8 & 0.86 \\
\hline Gestational age, weeks & $26(24-29)$ & $27(23-28)$ & 0.983 \\
\hline Birth weight, $\mathrm{g}$ & $856(484-1346)$ & $900(570-1130)$ & 0.621 \\
\hline Antenatal steroids & 13 & 13 & 0.58 \\
\hline Vaginal delivery & 12 & 9 & 0.19 \\
\hline Endotracheal tube & 6 & 5 & 0.6 \\
\hline Apgar at $1 \mathrm{~min}$ & $6(0-9)$ & $5(2-8)$ & 0.43 \\
\hline Apgar at $5 \mathrm{~min}$ & $8(5-10)$ & $8(4-10)$ & 0.98 \\
\hline Peak inspiratory pressure (PIP), $\mathrm{cmH}_{2} \mathrm{O}$ & $21.5(18.5-26.1)$ & $24(13.8-34.8)$ & 0.06 \\
\hline Positive end expiratory pressure (PEEP), $\mathrm{cmH}_{2} \mathrm{O}$ & $5.0(3.1-8.4)$ & $5.3(1.0-5.3)$ & 0.88 \\
\hline Inflation pressure, $\mathrm{cmH}_{2} \mathrm{O}$ & $15.9(12.6-22.9)$ & $19.2(12.8-29.7)$ & 0.07 \\
\hline VTi, $\mathrm{mL} / \mathrm{kg}$ & $3.3(0.9-176)$ & $7.7(3.1-21.9)$ & 0.06 \\
\hline Compliance, $\mathrm{mL} / \mathrm{cmH}_{2} \mathrm{O}$ & $0.05(0.01-1.2)$ & $0.184(0.02-0.3)$ & $<0.001$ \\
\hline Compliance, $\mathrm{mL} / \mathrm{cmH}_{2} \mathrm{O} / \mathrm{kg}$ & $0.06(0.02-0.14)$ & $0.37(0.02-0.59)$ & $<0.001$ \\
\hline Maximum $\mathrm{ETCO}_{2}$ level, $\mathrm{kPa}$ & $0.2(0.07-1.2)$ & $0.2(0.07-6.4)$ & 0.91 \\
\hline Leak, \% & $68(15-97)$ & $42(1-87)$ & 0.19 \\
\hline
\end{tabular}

Data are expressed as median (range) or $\mathrm{n}(\%)$.

Table 4: Comparison of facemask and endotracheal tube groups at $60 \mathrm{~s}$ into resuscitation.

\begin{tabular}{lrrr}
\hline & Facemask $(\mathrm{n}=11)$ & Endotracheal tube $(\mathrm{n}=18)$ & P-value \\
\hline Peak inspiratory pressure, $\mathrm{cmH}_{2} \mathrm{O}$ & $24.5(13.7-29.1)$ & $23.4(21.1-31)$ & 0.55 \\
Positive end expiratory pressure, $\mathrm{cmH}_{2} \mathrm{O}$ & $4.7(3.2-6.0)$ & $5.3(1.9-8.5)$ & 0.10 \\
Inflation pressure, $\mathrm{cmH}_{2} \mathrm{O}$ & $19.7(9.8-23.5)$ & $19.7(12.6-26)$ & 1.0 \\
Expiratory tidal volume, $\mathrm{mL} / \mathrm{kg}$ & $1.9(0.41-8.1)$ & $2.3(0.63-12.3)$ & 0.34 \\
Compliance, $\mathrm{mL} / \mathrm{cmH}_{2} \mathrm{O}$ & $0.1(0.01-0.4)$ & $0.1(0.02-0.5)$ & 0.74 \\
Compliance, $\mathrm{mL} / \mathrm{cmH}_{2} \mathrm{O} / \mathrm{kg}$ & $0.09(0.02-0.47)$ & $0.13(0.03-0.48)$ & 0.74 \\
Leak, \% & $67(10.7-99.4)$ & $45(3.2-86)$ & 0.028 \\
\hline
\end{tabular}

\section{Discussion}

We have demonstrated that, during the resuscitation at delivery of prematurely born infants, VTe levels before the first active inflation were low in infants resuscitated via an ETT or via an FM. These results suggest that there may be reasons other than airway obstruction for the low tidal volumes during initial FM resuscitation. In a previous study, in 10 preterm infants, VTi and VTe were larger during mask compared to endotracheal ventilation [12]. The authors postulated that this was due to distension of the upper respiratory tract contributing to the tidal volumes during mask ventilation, as they had calculated that in seven lambs the combined trachea and oropharynx contributed to $14 \%$ of the total tidal volume measured at the mouth [12]. They, however, assessed the infants for $2 \mathrm{~min}$ before and $2 \mathrm{~min}$ after intubation [12]. In contrast, we assessed the infants before they took their first breath (active inflation). We demonstrated no significant differences in the VTe or $\mathrm{ETCO}_{2}$ levels before the first active inflation between infants resuscitated via an ETT or an FM. Indeed, the VTe was as low as $0.59 \mathrm{~mL} / \mathrm{kg}$ in the FM group, suggesting that there was not significant oropharyngeal distension contributing to the tidal volume results during initial resuscitation. Indeed, the lack of significant difference in the $\mathrm{ETCO}_{2}$ results between the two groups further suggests that the VTe is from the lung and not the upper airway which is bypassed by the ETT. Furthermore, we did not demonstrate significant differences in the VTe before and after intubation in infants who had not made a respiratory effort. The difference between our results and those of the previous study may be explained by the fact that we examined initial resuscitation, that is, before the first breath, when both of our groups would have had low functional residual capacities.

A study of simulated FM resuscitation using a mannequin showed that, whilst complete airway obstruction was rare (0-2\% of cases), partial airway obstruction (defined 
as achieving a tidal volume less than $60 \%$ of the optimum tidal volume) was seen in approximately $40 \%$ of inflations [13]. Airway obstruction occurred frequently during efforts to minimise leak [13]. Use of an oropharyngeal airway in one study of initial resuscitation, however, did not abolish apparent complete or partial obstruction [14]. It has been suggested that FM ventilation is ineffective at aerating the lungs if there is laryngeal closure [15]. Indeed, in a recently reported study [16], phase contrast X-ray imaging showed that the glottis and epiglottis were predominately closed immediately after birth in apnoeic, prematurely born rabbits. Our results suggest that laryngeal closure does not always explain the low expiratory volumes before infants made a respiratory effort, as the VTes were similar in those resuscitated via an ETT or an FM. We propose that the low tidal volumes seen prior to the first active inflation may also be due to the currently advised inflation pressures when applied over short periods of time [3], which may be insufficient to overcome the resistance of fluidfilled small airways. In a previous study, we demonstrated that the time to the first active inflation correlated with the magnitude of the inflation pressure and the duration of the inflation [17]. Use of higher pressures and longer inflation durations were associated with higher tidal volumes [17]. The low $\mathrm{ETCO}_{2}$ levels before the first active inflation likely reflect that the pulmonary circulation was not fully vasodilated. We [18] and others [19-21] have shown $\mathrm{ETCO}_{2}$ levels increase when the infant makes inspiratory efforts.

The anatomical dead space in infants has been shown to be approximately $2.2 \mathrm{~mL} / \mathrm{kg}[1,2]$. Tidal volumes below this level may not make significant contributions to gas exchange. In addition, such low tidal volumes may not stimulate Head's paradoxical reflex which is important in resuscitation [4, 22]. Head's paradoxical reflex is stimulated when there is air entry into the lungs [23], 63\% of inflations in our study resulted in VTes of less than $2.2 \mathrm{~mL} / \mathrm{kg}$. We, therefore, compared the proportions of infants who had a median tidal volume below $2.2 \mathrm{~mL} / \mathrm{kg}$ in the two groups which were found to be similar, as was the proportion of inflations in the two groups which were associated with a VTe of less than $2.2 \mathrm{~mL} / \mathrm{kg}$.

There was a higher magnitude of leak in the FM group which may have led to the small tidal volumes. Repositioning of the FM may have reduced the leak. This, however, does not alter our conclusions. If the leak had been reduced by repositioning of the FM leading to larger expiratory volumes, this would confirm that clinically important airway obstruction was not a consistent feature of FM ventilation. An alternative explanation for lower VTes during FM resuscitation is that, in the presence of a large leak, there is lower pressure transmission.
There are strengths and some limitations to our study. We were able to compare VTe and $\mathrm{ETCO}_{2}$ levels in infants resuscitated either via an ETT or an FM. Whilst the infants included were heterogeneous in terms of gestational age and birth weight, the two groups of infants had similar demographics and compliance results and all were born extremely prematurely. It is possible that spontaneous respiratory efforts prior to the application of the FM or insertion of the ETT were missed. Nevertheless, the VTes were generally low before the first documented respiratory effort. In addition, the low levels of expired $\mathrm{CO}_{2}$ suggest that significant gas exchange had not occurred. We were also able to assess VTes before and after intubation in another group of infants demonstrating low VTes at both times. As these infants were their own controls, differences in lung function do not explain their results. The anatomical dead space might have been lower in the infants who were intubated as the upper airway was bypassed, but there were no significant differences in the VTe results in those studied before and after intubation. We included 29 infants in this retrospective analysis of previously collected respiratory function monitoring traces; our results, however, would inform a prospective study with a large sample size.

\section{Conclusion}

We have demonstrated similarly low VTe and $\mathrm{ETCO}_{2}$ levels in infants undergoing initial resuscitation via an ETT or an FM. In addition, the proportion of infants with a low VTe and the proportion of inflations with a low VTe were similar in the two groups. These results show that mechanisms other than upper airway obstruction can result in low tidal volumes during resuscitation. The infants with the lowest VTes had the stiffest lungs, further emphasising that initial resuscitation pressures may be inadequate. Respiratory function monitoring should be recommended in the delivery suite so clinicians can objectively identify low tidal volumes rather than rely on the subjective assessment of chest rise as indicating appropriate pressure delivery. Importantly, they must, however, be trained in the appropriate interpretation of the respiratory function monitoring [24].

Author contributions: AG, ADM, GF and MEC conceived and supervised the study and participated in the analysis of the data. KAH drafted the first version of the article. VM and PB collected the data. KAH, AG and ADM analysed the data. All authors were involved in the production of the final manuscript and approved its content. All the authors 
have accepted responsibility for the entire content of this submitted manuscript and approved submission.

Research funding: Dr. Hunt and Dr. Bhat were supported by the Charles Wolfson Charitable Trust and Dr. Hunt additionally by SLE. Dr. Murthy was supported by the Guy's and St Thomas' Charity. The research was supported by the National Institute for Health Research (NIHR) Biomedical Research Centre based at Guy's and St Thomas' NHS Foundation Trust and King's College London. The views expressed are those of the author(s) and not necessarily those of the NHS, the NIHR or the Department of Health.

Employment or leadership: None declared.

Honorarium: None declared.

Competing interests: The funding organisation(s) played no role in the study design; in the collection, analysis, and interpretation of data; in the writing of the report; or in the decision to submit the report for publication.

\section{References}

1. Lagneaux D, Mossay C, Geubelle F, Christiaens G. Alveolar data in healthy, awake neonates during spontaneous ventilation: a preliminary investigation. Pediatr Pulmonol 1988;5:225-31.

2. Numa AH, Newth CJ. Anatomic dead space in infants and children. J Appl Physiol 1996;80:1485-9.

3. Murthy V, Dattani N, Peacock JL, Fox GF, Campbell ME, Milner $A D$, et al. The first five inflations during resuscitation of prematurely born infants. Arch Dis Child Fetal Neonatal Ed 2012;97:F249-53.

4. Murthy V, D'Costa W, Shah R, Fox GF, Campbell ME, Milner $A D$, et al. Prematurely born infants' response to resuscitation via an endotracheal tube or a face mask. Early Hum Dev 2015;91:235-8.

5. Finer NN, Rich W, Wang C, Leone T. Airway obstruction during mask ventilation of very low birth weight infants during neonatal resuscitation. Pediatrics 2009;123:865-9.

6. Kaufman J, Schmölzer GM, Kamlin CO, Davis PG. Mask ventilation of preterm infants in the delivery room. Arch Dis Child Fetal Neonatal Ed 2013;98:F405-10.

7. Schmolzer GM, Dawson JA, Kamlin CO, O’Donnell CP, Morley CJ, Davis PG. Airway obstruction and gas leak during mask ventilation of preterm infants in the delivery room. Arch Dis Child Fetal Neonatal Ed 2011;96:F254-7.

8. Wood FE, Morley C. Face mask ventilation - the dos and don'ts. Semin Fetal Neonatal Med 2013;18:344-51.

9. Murthy V, D'Costa W, Shah R, Fox GF, Campbell M, Milner AD, et al. Prematurely born infants' response to resuscitation via an endotracheal tube or a face mask. Early Hum Dev 2015;91:235-8.
10. Perlman JM, Wyllie J, Kattwinkel J, Atkins DL, Chameides L, Goldsmith JP, et al. Neonatal Resuscitation Chapter Collaborators. Neonatal resuscitation: 2010 international consensus on cardiopulmonary resuscitation and emergency cardiovascular care science with treatment recommendations. Pediatrics 2010;126:e1319-44.

11. Murthy V, Rao N, Fox GF, Milner AD, Campbell ME, Greenough A. Survey of UK newborn resuscitation practices. Arch Dis Child Fetal Neonatal Ed 2012;97:F154-5.

12. van Vonderen JJ, Hooper SB, Krabbe VB, Siew ML, te Pas AB. Monitoring tidal volumes in preterm infants at birth: mask versus endotracheal ventilation. Arch Dis Child Fetal Neonatal Ed 2015;100:F43-6.

13. Schilleman K, Witlox RS, Lopriore E, Morley CJ, Walther FJ, te Pas $A B$. Leak and obstruction with mask ventilation during simulated neonatal resuscitation. Arch Dis Child Fetal Neonatal Ed 2010;95:F398-402.

14. Kamlin COF, Schmoelzer G, Dawson JA, McGrory L, O'Shea JE, Davis $P$. A randomized trial of oropharyngeal airways to assist stabilization of preterm infants in the delivery room (DR). In: European Respiratory Society International Congress, London, 2016. http://www.ers-education.org/events/internationalcongress/london-2016.aspx?idParent=151516.

15. van Vonderen JJ, Hooper SB, Hummler HD, Lopriore E, te Pas $A B$. Effects of a sustained inflation in preterm infants at birth. J Pediatr 2014;165:903-8.

16. Crawshaw JR, Kitchen MJ, Binder-Heschl C, Thio M, Wallace MJ, Kerr LT, et al. Laryngeal closure impedes non-invasive ventilation at birth. Arch Dis Child Fetal Neonatal Ed 2018;103:F112-9.

17. Harris C, Bhat P, Murthy V, Milner AD, Greenough A. The first breath during resuscitation of prematurely born infants. Early Hum Dev 2016;100:7-10.

18. Murthy V, O’Rourke-Potocki A, Dattani N, Fox GF, Campbell ME, Milner AD, et al. End tidal carbon dioxide levels during the resuscitation of prematurely born infants. Early Hum Dev 2012;88:783-7.

19. Palme-Kilander C, Tunell R. Pulmonary gas exchange during face mask ventilation immediately after birth. Arch Dis Child 1993;68:11-6.

20. Palme-Kilander C, Tunell R, Chiwei Y. Pulmonary gas exchange immediately after birth in spontaneously breathing infants. Arch Dis Child 1993;68:6-10.

21. van Vonderen JJ, Lista G, Cavigioli F, Hooper SB, te Pas AB. Effectivity of ventilation by measuring expired $\mathrm{CO}_{2}$ and RIP during stabilisation of preterm infants at birth. Arch Dis Child Fetal Neonatal Ed 2015;100:F514-8.

22. Hoskyns EW, Milner AD, Boon AW, Vyas H, Hopkin IE. Endotracheal resuscitation of preterm infants at birth. Arch Dis Child 1987;62:663-6.

23. Head H. On the regulation of respiration Part 1: Experimental. J Physiol 1889;10:1-152.

24. Milner A, Murthy V, Bhat P, Fox G, Campbell ME, Milner AD, et al. Evaluation of respiratory function monitoring at the resuscitation of prematurely born infants. Eur J Pediatr 2015;174:205-8. 